\title{
A PESCA DE LULAS (Mollusca: Cephalopoda) NA ILHA DO ARVOREDO (SC): CARACTERÍSTICAS E RELAÇÕES ECOLÓGICAS, VERÃO DE 1996.
}

\author{
PEREZ, J.A.A. ${ }^{1}$; SCHETTINI,C.A.F. ${ }^{1}$; BURATTO, J.R. ${ }^{2}$ \& MACHADO, M.J. ${ }^{3}$ \\ 1. Faculdade de Ciências do Mar - FACIMAR/UNIVALI. Cx.Postal 360, Itajaí, \\ SC, 88302-202 \\ 2. Acadêmico de Oceanografia (UNIVALI) \\ 3. Centro de Filosofia e Ciências Humanas-UFSC. Bairro Trindade - Florianópolis, \\ SC, 88.040-900
}

\begin{abstract}
RESUMO
Durante os meses de verão é marcada a presença de densas concentrações de lulas costeiras (Loligo plei) sobre a plataforma continental catarinense. Estas populações fern sustentado capturas industriais da ordem de 144 a 763 t por ano, e também deram origem â uma pescaria artesanal direcionada â esta espécie em torno das ilhas costeiras. Este estudo investiga as características dessa pescaria em torno da llha do Arvoredo $\left(48^{\circ} 22^{\prime} \mathrm{W} ; 27^{\circ} 17^{\prime} \mathrm{S}\right)$ e analisa a estrutura populacional das capturas bem como a dinâmica destas em relação aos fatores ambientais. Entre janeiro e março de 1996 foi estabelecido um sistema de monitoramento dos desembarques nas comunidades do Município de Governador Celso Ramos onde, através de entrevistas, foram obtidos dados das embarcações, artes e áreas de pesca, captura e esforço. Da mesma forma também foram realizadas 4 campanhas diurnas e uma noturna ao Saco do Capim (Ilha do Arvoredo) onde monitorou-se a captura por hora, direção e velocidade de corrente, e estrutura térmica da coluna de água. Amostras biológicas foram obtidas tanto das capturas comerciais quanto das capturas obtidas durante as campanhas ao Saco do Capim. A pesca ocorre em "bateiras" e "botes" que variam de 8 a $11 \mathrm{~m}$ de comprimento, dotados de motores de 9 a $24 \mathrm{HP}$ de potência e tripulados por 2 a 4 pescadores. A captura se dá através de linhas de mão com "zangarilhos" (tipo de garatéia de chumbo não iscada) e cada pescador opera de 2 a 4 linhas. Essas embarcações atuam preferencialmente no Saco do Capim em profundidades de 10 a $20 \mathrm{~m}$. As viagens duram em media $33 \mathrm{~h}( \pm 12,4 \mathrm{DP})$ com atividade pesqueira ocorrendo tanto durante o dia, quando as capturas ocorrem no fundo, quanto â noite, quando utiliza-se atração luminosa para a pesca em superfície. O rendimento e a captura por unidade de esforço médios foram de $49,6 \mathrm{Kg}$ por viagem $( \pm 56,4 \mathrm{DP}, \mathrm{n}=35)$ e $0,56 \mathrm{Kg}^{\text {. pescador }}{ }^{-1}$. hora ${ }^{-1}( \pm 0,71 \mathrm{DP})$ respectivamente. A dinâmica das capturas mostrou picos marcados em função principalmente de flutuações temporais nas concentrações de lula. Capturas durante as campanhas ocorreram: (a) tanto em condições de coluna de água homogênea como estratificada, (b) em temperaturas entre 18 e $26^{\circ} \mathrm{C}$, e (c) quando as camadas sub-superficiais de água no Saco do Capim fluiam para SW. A maioria dos machos e fêmeas capturados encontravam-se em estágios avançados de maturação gonadal.
\end{abstract}

Palavras-Chave: Loligo plei, Loliginidae, Pesca, Santa Catarina, Brasil.

\section{LOLIGINID SQUID FISHERY AROUND ARVOREDO ISLAND (SANTA CATARINA, BRASIL): CHARACTERISTICS AND ECOLOGICAL RELATIONSHIPS, SUMMER 1996.}

\begin{abstract}
During the austral summer, important concentrations of the long-finned squid, Loligo plei, occur on the continental shelf off Santa Catarina State, southern Brazil. These populations have sustained offshore annual catches ranging from 144 to 763 metric tonnes, and have originated an inshore artisan fishery around the coastal islands. This report describes this fishery around the Arvoredo Island ( $\left.48^{\circ} 22^{\prime} \mathrm{W} ; 27^{\circ} 17^{\prime} \mathrm{S}\right)$ and analizes: (a) the dynamics of catches in relation to environmental fluctuations and (b) the population structure of catched squid. Information on boat features, fishing
\end{abstract}




\begin{abstract}
techniques, fishing areas, catch and effort were obtained between January and March 1996, from interviews with fishermen during landings at the locality of Governador Celso Ramos. Squid samples were obtained from commercial catches and from five sampling trips conducted in the main fishing area off Arvoredo Island during the same period. During each trip surface and subsurface currents speed and direction as well as the thermal structure of the water column were continuously monitored. The inshore fishery is conducted by 9 to $11 \mathrm{~m}$ long boats known as "botes" or "bateiras", powered by 9 to 24 HP engines. Squid is captured by hand lines and a type of jig called "zangarilhos" which are operated by 2 to 4 men on each boat. Fishing takes place mainly on 10 to $20 \mathrm{~m}$ deep grounds located in the southeastern shore of the island in an area known as "Saco do Capim", where boats anchor for $33 \mathrm{~h}( \pm 12,4 \mathrm{SD})$ on average per trip. Catches occur either during the day (bottom fishing) or at night when the boat lights are used to attract squids to the surface. Mean catch and mean catch per unit of effort were $49,6 \mathrm{Kg}$ per trip $( \pm 56,4 \mathrm{SD}, \mathrm{n}=35)$ and $0,56 \mathrm{Kg} \mathrm{mar}^{-1}$.hour ${ }^{-1}( \pm Q, 71 \mathrm{SD})$ respectively. Commercial catches showed marked temporal peaks as a response to fluctuations on the squid occurrence in the area. Squid were catched: (a) in either homogenized or stratified water column; (b) at temperatures ranging from 18 to $26^{\circ} \mathrm{C}$; and (c) when subsurface water layers were flowing $\mathrm{SW}$ off the island shore. Most males and females caught were in advanced sexual maturity stages.
\end{abstract}

Key-Words: Loligo plei, Loliginidae, Fishery, Santa Catarina, Brazil.

\section{INTRODUÇÃO}

Loliginídeos habitam áreas costeiras e de plataforma continental onde sustentam pescarias locais (Guerra \& Gandaras, 1983; Coelho, 1985). Ao longo da costa Sudeste- Sul do Brasil, duas espécies, Loligo plei e Loligo sanpaulensis, ocorrem em concentrações importantes e representam recursos pesqueiros potenciais (Haimovici \& Andriguetto, 1986; Costa \& Haimovici, 1990; Haimovici \& Perez, 1991a e b). Essas espécies são capturadas pela pesca industrial de arrasto e artesanalmente, constituindo os principais componentes dos desembarques de cefalópodes nos estados do Rio de Janeiro, São Paulo, Santa Catarina e Rio Grande do Sul (Costa \& Haimovici, 1990). Tais desembarques aumentaram, entre 1976 e 1986 , em mais de $300 \%$ atingindo cerca de 2.000 toneladas anuais.

Esses loliginídeos estão presentes nas capturas incidentais da frota de arrasteiros (parelhas e camaroneiros) e são desembarcados em Itajaí e Navegantes ao longo de todo o ano. As capturas oscilaram, de 1988 a 1994, entre 144 a 763 toneladas (CEPSUL/ IBAMA, 1994' sendo que a maior parte desse rendimento tem sido sustentado por densas concentrações de $L$. plei que ocorrem sobre a plataforma continental durante os meses de verão. Durante esse período, L. plei pode representar ate $4,5 \%$ do total capturado pela frota industrial de ar- rasteiros (Perez, 1996). Concentrações estivais costeiras de L. plei também estimularam o desenvolvimento de uma pescaria artesanal sediada principalmente ao longo do litoral da llha de Florianópolis e da Baía de Tijucas incluindo os municípios de Governador Celso Ramos, Porto Belo e Bombinhas. Pes-cadores engajados nessa atividade utilizam pequenas embarcações, linhas-de-mão e "zangarilhos" (tipo de garatéia) e atuam de janeiro à março, principalmente em torno das ilhas costeiras em profundidades inferiores $20 \mathrm{~m}$ (Perez et al., 1996). Uma análise das estatísticas de desembarques disponíveis nos bancos de dados do IBAMA (Perez, 1996) mostrou que, durante o primeiro trimestre de 1988 a 1994, a pesca artesanal de lula produziu no mínimo 33,8 a 134,4 toneladas, as quais atingiram ate $5,5 \%$ do total produzido pela pesca artesanal de verão em Santa Catarina. Embora outros registros dessa atividade existam na costa sudeste-sul do Brasil, a pescaria artesanal de lulas em Santa Catarina parece ser a mais importante do ponto de vista cultural e econômico (Perez et al., 1996) necessitando um melhor entendimento de sua magnitude e suas relações com o ambiente natural. Como parte de um projeto em andamento que estuda a dinâmica das populações de $L$. plei da costa catarinense e o impacto da pesca sobre 
essas populações, o presente relatório descreve a atividade da pesca artesanal desta espécie na Ilha do Arvoredo e arredores. Essa área, que constitui um dos principais focos de concentração dessa atividade, também merece especial interesse visto que engloba o entorno de uma área de reserva ambiental e, portanto, demanda um conhecimento aprofundado dos possíveis impactos ambientais antrópicos. Pretende- se, também, discutir dados de um estudo piloto que visou abordar as causas naturais das concentrações de lulas em torno da ilha. Como hipótese de trabalho, propõe-se que $L$. plei concentra-se nessa área: (a) em busca de fundos apropriados para a desova, (b) em busca de alimento, principalmente concentrações de juvenis de peixes pelágicos, e (c) em função de condições oceanográficas particulares que originam-se do efeito de massa da ilha sobre os regimes oceangráficos costeiros. Neste relatório serão apresentados dados que exploram a primeira e a terceira hipóteses, e que resultaram de um programa de amostragem na principal área de pesca da ilha.

\section{MATERIAL E MÉTODOS}

A pescaria artesanal de lulas na Ilha do Arvoredo foi descrita a partir de dados coletados entre 19 de janeiro e 10 março de 1996 nas comunidades do Município de Governador Celso Ramos, o qual concentra a grande maioria dos pescadores engajados nessa atividade. Foi estabelecido um sistema de monitoramento dos desembarques onde, através de entrevistas, foram obtidos os seguintes dados (ver Anexo 1):

\section{Sobre as embarcações:}

- Comprimento total (em metros)

- Potência do motor (em HP)

Sobre a atividade pesqueira:

- Áreas de pesca e profundidade estimada (em metros)

- Duração da pescaria (desconsiderando-se o tempogasto na navegação, descanso ou abrigo)
- Período do dia (diurno, noturno, ambos)

- Número de pescadores em cada embarcação

- Rendimento total (em quilogramas)

Com estes dados, calcularam-se medidas de esforço pesqueiro e captura por unidade de esforço (CPUE) em pescador. hora $^{-1}$ e kg.pescador ${ }^{-1}$. hora-1 ${ }^{-1}$ respectivamente.

O estudo das concentrações de lula em torno da Ilha do Arvoredo foi realizado através de 4 campanhas diurnas e uma noturna ao Saco do Capim, costa sul-sueste da ilha, onde se concentra o maior número dos barcos. As viagens tiveram duração aproximada de 6 horas e foram realizadas em um bote de 9 metros tripulado por 5 a 7 pessoas. A amostragem foi efetuada através da captura de lulas com o uso de linha de mão e "zangarilho", por todas as pessoas à bordo durante o tempo total de permanência no Saco do Capim. Além da captura do barco amostrador, monitorou-se visualmente a captura de lulas das embarcações próximas. As contagens de lulas capturadas eram registradas a cada meia hora. O esforço foi calculado levando-se em consideração o número de pescadores atuando em cada embarcação monitorada e a captura em número de lulas. Assim a CPUE, durante as campanhas, foi expressa em número de lulas.pescador ${ }^{-1}$.hora $^{-1}$. Os dados de captura das quatro últimas viagens foram complementados com as seguintes informações ambientais:

(a) direção e velocidade da corrente, registradas continuamente através do fundeio de correntógrafos Sensordata SD6000 ${ }^{\circledR}$. Durante a viagem realizada em 25 de janeiro, o fundeio foi feito apenas com um correntógrafo posicionado a 2 metros acima do fundo. Essa configuração foi adotada em função do hábitat diurno das lulas ser próximo ao fundo. Nas demais viagens foram fundeados dois correntógrafos, a 2 e a 10 metros acima do fundo.

(b) a estrutura térmica da coluna de água, obtida através de perfis de tempera-tura medidos a cada metro e a cada hora usando um medidor de temperatura e condutividade 
YSI ${ }^{\circledR}$. Os dados de condutividade não apresentaram consistência, provavelmente devido à problemas com o instrumento, não sendo então utilizados nesse trabalho.

A estrutura populacional das capturas foi analizada através da distribuição de comprimentos das amostras biológicas bem como do estado reprodutivo dos indivíduos capturados. A bionnetria dos indivíduos capturados incluiu o comprimento dorsal do manto (CM) e o peso total $(P)$. Estágios qualitativos de maturação gonadal foram determinados de acordo com a escala proposta por Juanicó (1983) e adaptada para L. plei. Em fêmeas, esta escala se baseia no tamanho relativo do ovário, glândulas nidamentais e oviducais assim como a presença de ovos nos ovários e ovidutos. Em machos, foram considerados o tamanho relativo dos testículos e a presença de espermatóforos no saco espermatofórico. A presença de espermatóforos na região bucal das fêmeas foi considerado um indicativo de atividade sexual.

\section{RESULTADOS}

\section{Características da pescaria artesanal de lulas na llha do Arvoredo}

Os dados brutos provenientes do monitorannento dos desembarques no Município de Governador Celso Ramos (Fig. 1) estão apresentados no Anexo II. Foram obtidas informações de um total de 35 desembarques realizados nas localidades de Ganchos de Fora, Ganchos do Meio e Canto dos Ganchos. A pesca ocorre em "bateiras" e "botes" que variam de 8 a $11 \mathrm{~m}$ de comprimento, apresentam motores de 9 a 24 HP de potência e são tripulados por 2 a 4 pescadores (Tabela 1). A captura se dá através de linhas de mão com "zangarilhos" que são garatéias de chumbo não iscadas de aproximadamente oito centímetros de comprimento, forma

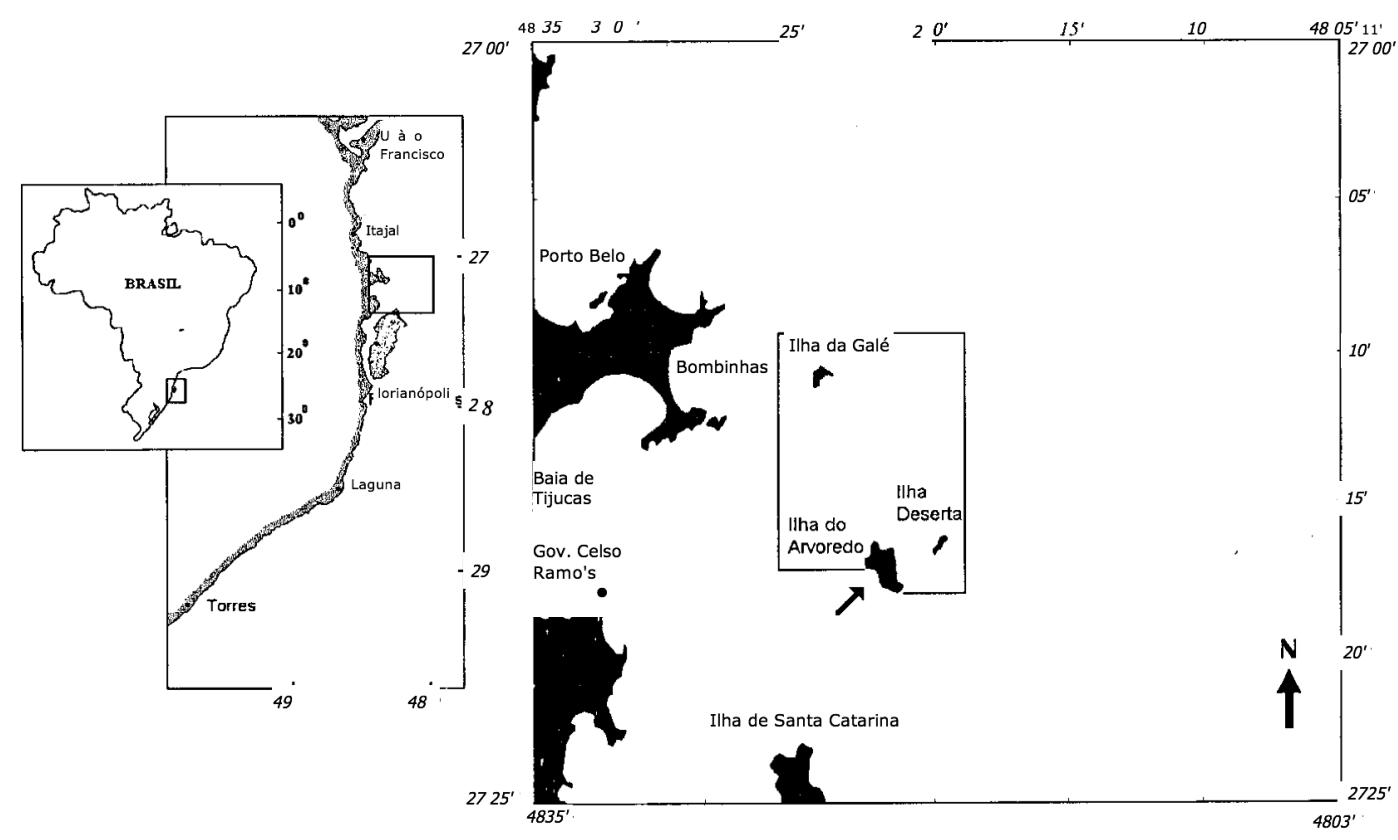

Figura 1 - Área de estudo incluindo: a área de concentração da pesca da lula no entorno da llha do Arvoredo (Saco do Capim, indicado pela seta), a área incluída pela Reserva Biológica do Arvoredo (delimitada pela linha contínua) e as comunidades onde estão sediados os pescadores de lula. 
Tabela 1 - Sumário dos dados pesqueiros obtidos através de entrevistas com pescadores durante os desembarques nas comunidades do Município de Gov. Celso Ramos. $n$, número amostrai; DP, desvio padrão.

\begin{tabular}{lccccc}
\hline & $\mathrm{n}$ & Média & $\mathrm{DP}$ & Máx. & Min. \\
\hline Comprimento da Embarcaçao $(\mathrm{m})$ & 33 & 8,9 & 0,59 & 11 & 8 \\
Potência do motor (HP) & 35 & 16,0 & 3,91 & 24 & 9 \\
No. de Pescadores & 35 & 2,8 & 0,72 & 5 & 1 \\
Profundidade de Pesca (m) & 31 & 16,8 & 3,39 & 20 & 15 \\
Duraçao da Pescaria (h) & 34 & 33,4 & 12,39 & 60,5 & 4,5 \\
Captura (kg) & 34 & 49,6 & 56,41 & 200 & 0 \\
Esforço (pescador. $\mathrm{h}^{-1}$ ) & 35 & 92,6 & 36,52 & 181,5 & 0 \\
CPUE (kg.pescado ${ }^{-1} \cdot \mathrm{h}^{-1}$ ) & 34 & 0,6 & 0,71 & 3,51 & 0 \\
\hline
\end{tabular}

cônica e cobertas por fio de nylon branco por vezes com bandas de uma outra cor (verde, vermelho, azul). Cada pescador pode operar de 2 a 4 linhas ao mesmo tempo. Essas embarcações atuam fundeadas preferencialmente no Saco do Capim, costa sul-sueste da llha do Arvoredo, em profundidades de 10 a 20 m. Capturas consideráveis também ocorreram em torno à llha de Florianópolis nas localidades de Barra da Lagoa, Praia dos ingleses e Praia do Santinho. No Saco do Capim, as concentrações de lulas podem atrair muitas embarcações que chegam a estar fundeadas a menos de cinco metros de distância entre si. Durante o período estudado, um máximo de 29 embarcações operando ao mesmo tempo foi contado durante o dia. Relatos de pescadores locais mencionam concentrações de embarcações ainda maiores em anos anteriores. As viagens duraram em média 33h ( \pm 12,4 DP) com atividade pesqueira ocorrendo tanto durante 0 dia, quando a captura ocorre no fundo, como à noite quando se utiliza atração luminosa $e$ pesca- se na superfície. A atração luminosa consiste de lampiões a gás propano ou, como tem sido mais utilizado recentemente, lâmpadas fluorescentes ativadas pela energia elétrica da bateria do motor. Sediadas principalmente nas localidades dos municípios de Governador Celso Ramos e Bombinhas (Fig. 1), as embarcações navegam em torno de 1 hora e quarenta minutos para desem-barcar a captura, mantida no gelo, diretamente nas peixarias para compradores locais. Durante grande parte do período amostrado o preço oferecido ao pescador foi de $\mathrm{R} \$ 2,50$ (aproximadamente US\$ 2,50) por quilo.

$\mathrm{O}$ rendimento e a CPUE médios foram de 49,6 $\mathrm{kg}$ por viagem $( \pm 56,4 \mathrm{DP}, n=$ 35) e 0.56 kg.pescador ${ }^{-1} \cdot$ hora $^{-1}$ ( $\pm 0,71$ DP) respectivamente (Tabela 1 ). A captura máxima chegou a $200 \mathrm{~kg}$ por viagem sendo que $70 \%$ dos desembarques, no entanto, foram inferiores a $40 \mathrm{~kg}$ (Fig. 2a). A CPUE mais elevada foi de 3,6 kg. pescador ${ }^{-1}$. hora $^{-1}$ e $70 \%$ das viagens apresentaram CPUE in-ferior a 0,6 kg.pescador ${ }^{-1}$. hora-1 (Fig. 2b).

\section{Dinâmica da pescaria de lulas na llha do Arvoredo durante o verão de 1996}

A dinâmica das capturas mostrou picos em função principalmente de variações temporais nas concentrações de lula. A freqüência de desembarques foi maior no início do período amostrado (Fig. 3a) sendo que aparentemente tinha sido bastante alta também durante as duas primeiras semanas de janeiro, as quais não foram monitoradas. Um pequeno pico nos desembarques repetiu-se no fim de fevereiro após o qual a frota, desestimulada pelas quedas no rendimento de lula, deslocou-se para a pesca de arrasto do camarão sete-barbas e juvenis de camarão-rosa junto à costa. Os rendimentos e a CPUE foram menos elevados durante os dias de maior atividade, possivelmente em função do maior número de embarcações operando no Saco do Capim. O rendimento e a CPUE das duas embarcações que operaram nessa área no início de fevereiro foram maiores que os obtidos no início de janeiro (Fig. 3 b e c). 
2.A.
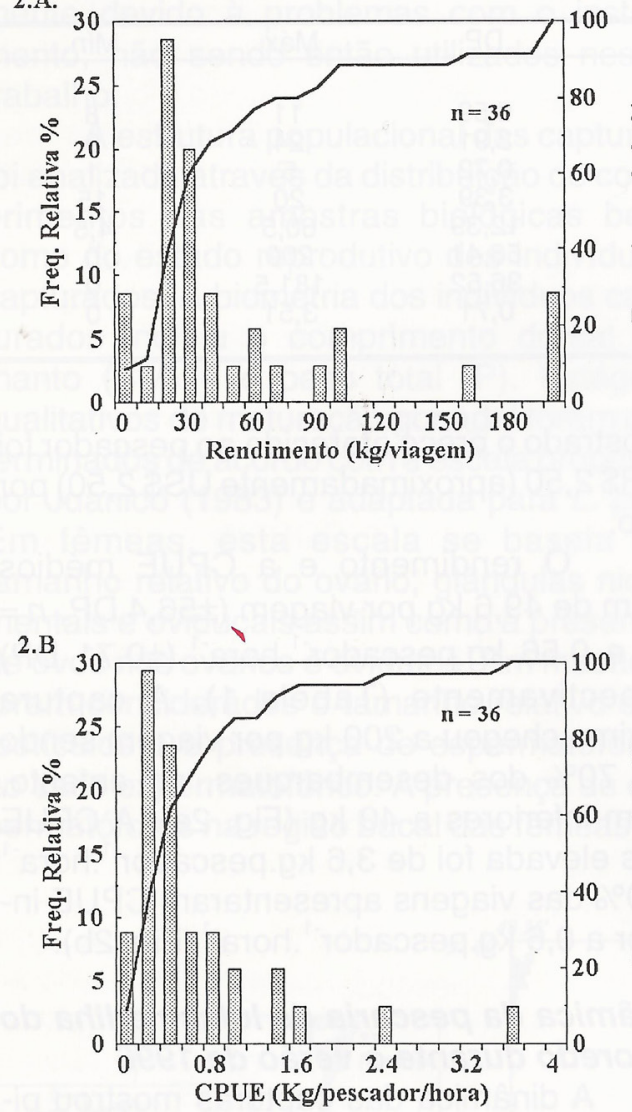

Figura 2 - Distribuição da frequência relativa (barras) e acumulada (linha) dos rendimentos (A) e da CPUE (B) registrados nos desembarques nas localidades do $\mathrm{Mu}-$ nicípio de Gov. Celso Ramos entre 19 de janeiro e 10 de março de 1996.

Outras capturas elevadas, registradas no fim do período monitorado, ocorreram nas áreas de entorno da llha de Florianópolis.

As amostragens de lula no Saco do Capim também refletiram a dinâmica do desembarque citada acima. Maiores rendimentos e CPUE (até 19,43 lulas.pescado-1. hora $^{-1}$ nos horários de pico), ocorreram na primeira campanha no dia 19 de janeiro (Fig. 4a). Nas duas viagens subseqüentes, dias 25 e 31 de janeiro, não foi capturada uma só
3.A
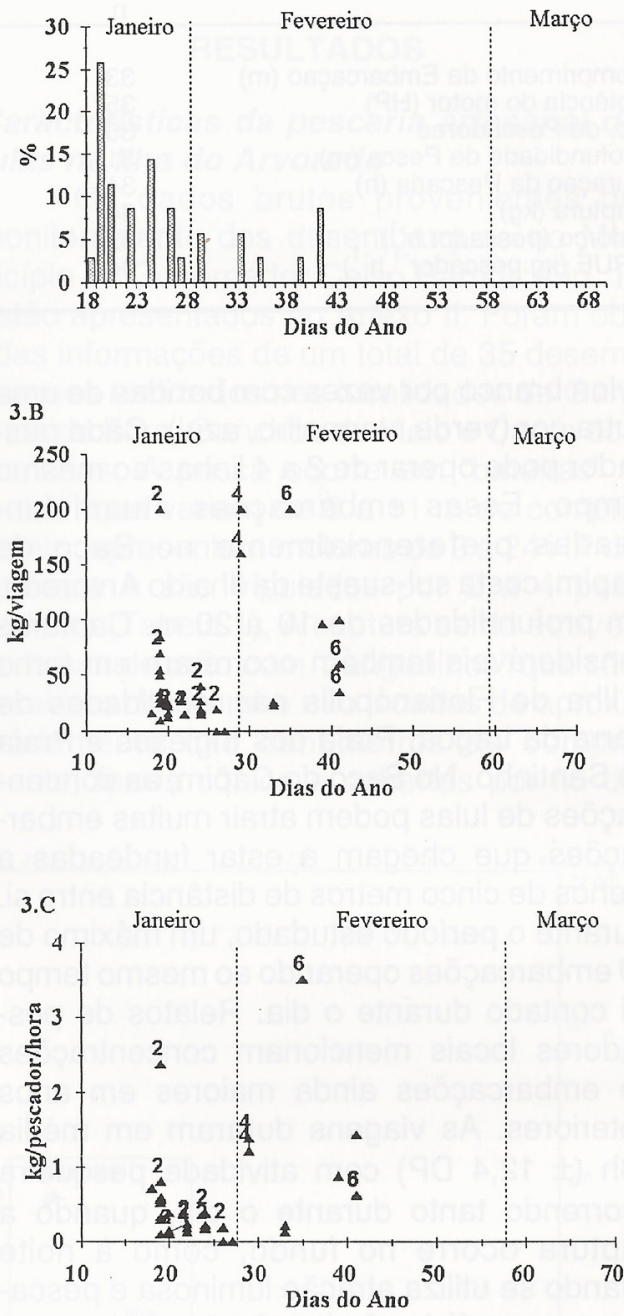

Figura 3. Variação diária da pesca artesanal de lula na área de entorno da Ilha do Arvoredo e arredores registrados nos desembarques nas localidades do Município de Governador Celso Ramos entre 19 de janeiro e 10 de março de 1996. A, distribuição de frequência relativa dos desembarques; B, rendimento; C, CPUE. 2, Praia dos Ingleses; 3, Barra da Lagoa; 4, Praia do Santinho; 5, Saco d'água; 6, Ilha das Aranhas. Triângulos não numerados correspondem a capturas no Saco do Capim.

lula durante todo o periódo diurno amostrado. Rendimentos e CPUE menores ocorreram na última viagem diurna e na única viagem 

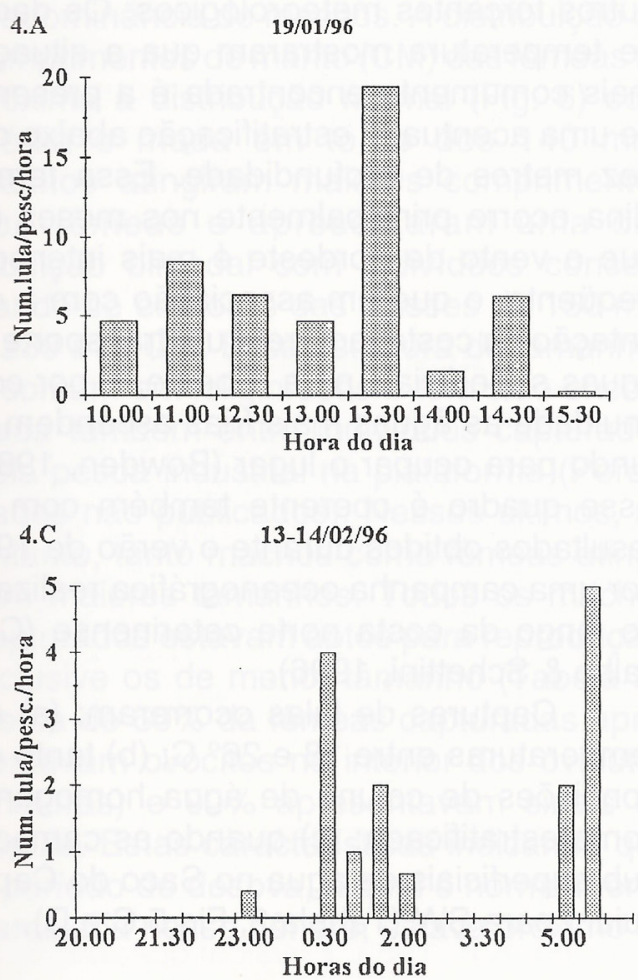

noturna, dias 8 e 13-14 de fevereiro respectivamente (Fig. $4 \mathrm{~b} \mathrm{e} \mathrm{c}$ ). Durante os períodos de amostragem, a dinâmica da captura de lulas também mostrou que a ocorrência de lulas na área do Saco do Capim dá-se em breves pulsos durante os quais normalmente observa-se um grande aumento na atividade de pesca de todos os barcos operando na área.

\section{Condições ambientais na área de ocorrência de lula}

As condições oceanográficas observadas durante as quatro últimas viagens à Ilha do Arvuredo estão sumarizadas na tabela 2. Foi utilizado um coeficiente de estratificação, $C_{E}$, para caraterizar a variação da temperatura ao longo da coluna de água e evidenciar a presença de diferentes massas de água. Esse coeficiente é determinado por:

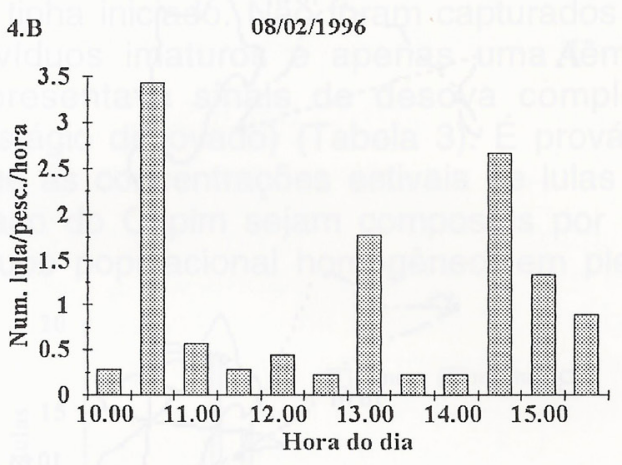

Figura 4 - Variação temporal da CPUE durante os períodos de amostragem no Saco do Capim, Ilha do Arvoredo. A, 19/01; B, 08/02; C, 13-14/02 (noite).

$$
C_{E}=\frac{T_{S}-T_{F}}{\bar{T}}
$$

onde $T_{S}$ e $T_{E}$ são as temperaturas médias da superfície e do fundo respectivamente, e $\boldsymbol{T}$ é a temperatura média de toda a coluna de água. Para uma situação de coluna de água homogênea, sem diferença vertical de temperatura, o coeficiente será zero. Quanto maior for a diferença entre a superfície e o fundo, maior será o valor do coeficiente. Valores positivos ocorrerão quando a temperatura da água diminui com a profundidade, do contrário, os valores serão negativos.

Na tabela 2, os dados de velocidade de corrente foram reduzidos em médias absolutas. Na figura 5, os dados de corrente estão representados como deslocamento lagrangeano para realçar diferenças entre vários níveis de coleta. Devido ao tempo de permanência do fundeio ser determinado pelo período de amostragem de lulas, não foi possível obter dados referentes aos ciclos completos de maré. Dessa forma, tornou-se 
$A$

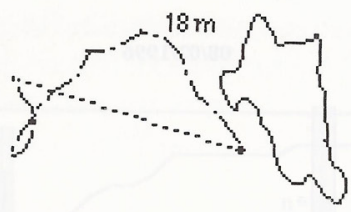

B

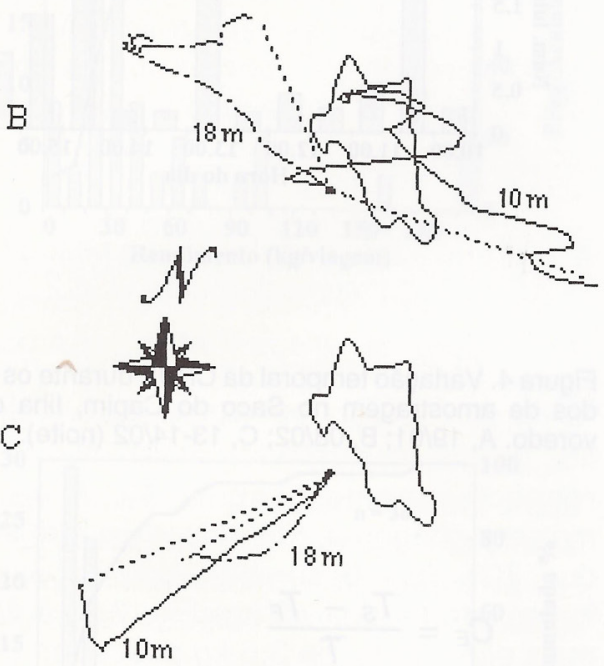

C
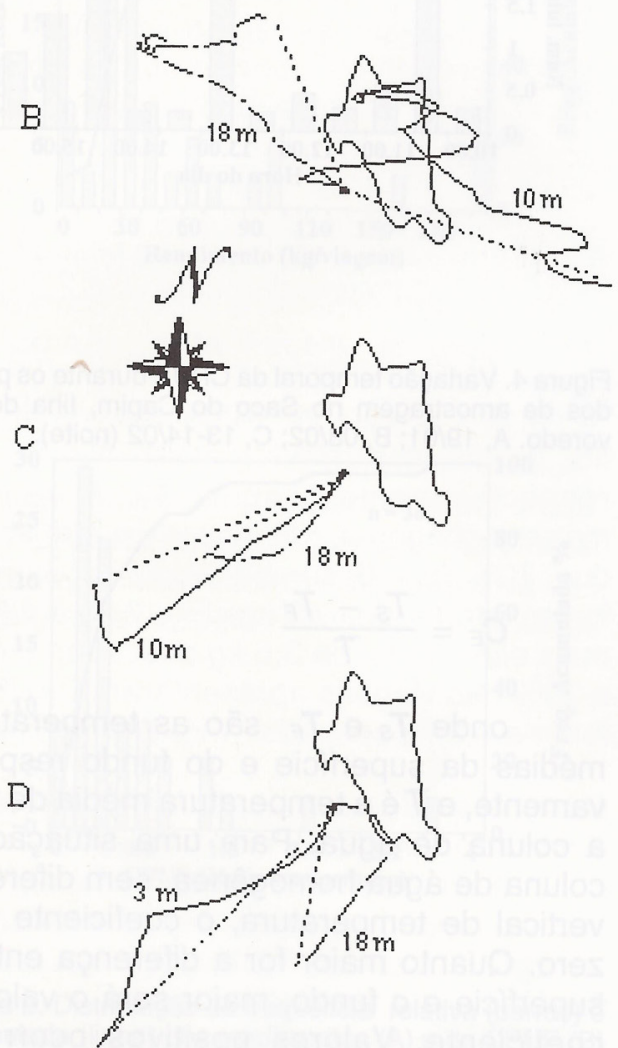

Figura 5 - Deslocamento lagrangeano residual das correntes no Saco do Capim (Illha do Arvoredo) durante quatro amostragens de lula no verão de 1996. A, 25/01; B, 31/01; C, 08/02 (CPUE = 1,03 $\pm 1,03$ DP lulas.pescado $^{-1} \cdot$ hora $^{-1}$ ); D, 13-14/02 (noite, CPUE $=1,08 \pm 1,06$ DP lulas.pescador ${ }^{-1} \cdot$ hora $\left.^{-1}\right)$. dificil avaliar quais os padrões de corrente devido a maré e quais os padrões devido a outros forçantes meteorológicos. Os dados de temperatura mostraram qua a situação mais comumente encontrada é a presença de uma acentuada estratificação abaixo dos dez metros de profundidade. Essa termoclina ocorre principalmente nos meses em que o vento de nordeste é mais intenso e freqüente, o que em associação com a orientação da costa, acarreta um transporte de águas superficiais para o oeste, e por continuidade as águas mais frias ascendem do fundo para ocupar o lugar (Bowden, 1983). Esse quadro é coerente também com os resultados obtidos durante o verão de 1995 por uma campanha oceanográfica realizada ao longo da costa norte catarinense (Carvalho \& Schettini, 1996).

Capturas de lulas ocorreram: (a) em temperaturas entre 18 e $26^{\circ} \mathrm{C}$; (b) tanto em condições de coluna de água homogênea como estratificada; (c) quando as camadas sub-superficiais de água no Saco do Capim fluiam para SW (Tabela 2; Fig.5 C e D).

\section{Estrutura populacional e estado reprodutivo das capturas}

Foram amostradas 74 fêmeas (101 194 mm CM; 22,7 - 99,9 g P) e 27 machos (126 - 271 mm CM; 33,3- 169 g P) de L. piei oriundos de capturas no Saco do Capim. A ocorrência de fêmeas nas capturas no Saco do Capim foi cerca de três vezes mais freqüente do que de machos (Tabela 3). Esta tendência foi evidenciada também na amostra proveniente da captura comercial

Tabela 2 - Sumário das caraterísticas oceanográficas no Saco do Capim (Ilha do Arvoredo) durante quatro campanhas de amostragem de lula no verão de 1996. Unidades: Temperatura, ${ }^{\circ} \mathrm{C}$; Velocidade da corrente, $\mathrm{cm}^{-\mathrm{s}^{-1}}$; Captura de lulas por unidade de esforço (CPUE), lulas. pescador ${ }^{-1}$.hora ${ }^{-1}$.

\begin{tabular}{|c|c|c|c|c|c|}
\hline Campanha & $\begin{array}{l}\text { Temperatura } \\
\text { máx. - min. }\end{array}$ & $\begin{array}{l}\text { Coeficiente de } \\
\text { Estratificaçao }\end{array}$ & $\begin{array}{l}\text { Velocidade da } \\
\text { Corrente }\end{array}$ & $\begin{array}{l}\text { Direçäo } \\
\text { do Vento }\end{array}$ & CPUE \\
\hline $25 / 01$ & $27,0-17,0$ & 0,35 & 6,4 & N & 0 \\
\hline $31 / 01$ & $27,5-18,0$ & 0,38 & 4,1 & N & 0 \\
\hline $08 / 02$ & $27,5-18,5$ & 0,36 & 6,3 & $N$ & $1,03 \pm 1,03$ \\
\hline $12-13 / 01$ & $26,0-24,0$ & $-0,02$ & 17,5 & SW & $1,08 \pm 1,06$ \\
\hline
\end{tabular}


(10/02) e não foi observada apenas na terceira viagem (09/02) quando houve uma leve predominância de machos. A distribuição de comprimentos de manto $(\mathrm{CM})$ das fêmeas foi próxima à distribução normal (Fig. 6) com média e moda em torno dos $140 \mathrm{~mm}$. Machos atingiram maiores comprimentos que fêmeas e apresentaram uma distribuição bimodal com indivíduos concentrando-se em torno das classes de $150 \mathrm{~mm}$ e $230 \mathrm{~mm}$ CM. Essa estrutura de tamanhos é comum em loliginídeos e tem sido encontrada também entre indivíduos capturados pela pesca industrial na plataforma (Perez, dados não publicados). Nesses últimos, no entanto, tanto machos como fêmeas atingiram maiores tamanhos. Todos os machos capturados estavam aptos para reprodução, inclusive os de menor tamanho (Tabela 3). Cerca de $60 \%$ da fêmeas capturadas apresentavam ovócitos no interior dos ovidutos (maturas) e $90 \%$ apresentavam sinais de cópula. Estas características indicaram que o período de desova, a qual é normalmente parcelada nesse gênero, estava próximo ou já tinha iniciado. Não foram capturados indivíduos imaturos e apenas uma fêmea apresentava sinais de desova completa (estágio desovado) (Tabela 3). É provável que as concentrações estivais de lulas no Saco do Capim sejam compostas por um grupo populacional homogêneo, em pleno

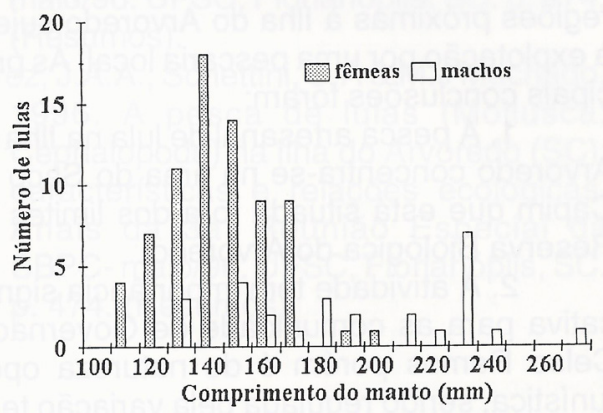

Figura 6 - Distribuição de comprimentos do manto (em $\mathrm{mm}$ ) de machos e fêmeas de Loligo plei, capturados no Saco do Capim durante o verão de 1996.

Tabela 3 - Sumário das características biológico-populacionais das amostras de Loligo plei capturadas no Saco do Capim (llha do Arvoredo) durante o verão de 1996. O número amostrai ( $n$ ), o comprimento do manto (CM) e pesos médios ( $\pm \mathrm{DP}$ ) estão apresentados nas primeiras três colunas. A frequência absoluta e a frequência relativa (em \%, entre parênteses) dos estágios de maturação sexual para machos e fêmeas, estão apresentadas nas quatro colunas seguintes. O estágio "desovado" em machos corresponde ao de liberação completa dos espermatóforos. As frequências de fêmeas "fertilizadas" estão representadas na última coluna e correspondem à presença de espermatóforos nos receptáculos bucais das fêmeas. *, a amostra biológica do dia 9 de fevereiro, foi obtida de uma captura comercial.

\begin{tabular}{|c|c|c|c|c|c|c|c|c|}
\hline \multirow[b]{2}{*}{ Amostra } & \multirow[b]{2}{*}{$n$} & \multirow[b]{2}{*}{$\begin{array}{c}\mathrm{CM} \\
(\mathrm{mm})\end{array}$} & \multirow[b]{2}{*}{$\begin{array}{c}\text { Peso } \\
\text { (g) }\end{array}$} & \multicolumn{5}{|c|}{ Estágio de Maturação } \\
\hline & & & & Imaturo & $\begin{array}{c}\text { Em } \\
\text { maturação }\end{array}$ & Maturo & Desovado & Fertilizadas \\
\hline $\begin{array}{l}\text { Femeas } \\
19 \text { jan. } \\
25 \text { jan. } \\
31 \text { jan. }\end{array}$ & $\begin{array}{c}21 \\
0 \\
0\end{array}$ & $56,7 \pm 16,4$ & $60,1 \pm 16,0$ & $0(0,0)$ & $5(23,8)$ & $16(76,2)$ & $0(0,0)$ & $21(100,0)$ \\
\hline 08 fev. & 7 & $148,3 \pm 10,4$ & $58,8 \pm 12,6$ & $0(0,0)$ & $1(14,3)$ & $6(85,7)$ & $0(0,0)$ & $7(100,0)$ \\
\hline 09 fev." & 31 & $129,2 \pm 16.3$ & $41,6 \pm 10,6$ & $0(0,0)$ & $19(61,3)$ & $11(35,7)$ & $1(3,2)$ & $26,(83,9)$ \\
\hline $13-14 \mathrm{fev}$ & 15 & $133,3 \pm 9,7$ & $41,8 \pm 7,2$ & $0(0,0)$ & $4(26,7)$ & $11(73,3)$ & $0(0,0)$ & $14(93,3)$ \\
\hline Total & 74 & $139,6 \pm 18,8$ & $48,5 \pm 14,8$ & $0\{0,0\}$ & $29(39,2)$ & $44(59,4)$ & $1(3,2)$ & $68(91,9)$ \\
\hline $\begin{array}{l}\text { Machos } \\
19 \text { jan. }\end{array}$ & 7 & $2154+370$ & $1015+40.5$ & $0(0,0)$ & $0(0,0)$ & $7 / 10001$ & לו & \\
\hline $25 \mathrm{jan}$. & 0 & & & $0(0,0)$ & $(0,0)$ & $R(100,0)$ & $0(0,0)$ & \\
\hline $31 \mathrm{jan}$. & $\begin{array}{c}0 \\
10\end{array}$ & & & & & & & \\
\hline 08 lov. & 10 & $180,3 \pm 40,0$ & $74,9 \pm 37,1$ & $0(0,0)$ & $1(10,0)$ & $8(80,0)$ & $1(10,0)$ & \\
\hline 00 lov. ${ }^{*}$ & 8 & $168,4 \pm 33,5$ & $64,2 \pm 29,5$ & $0(0,0)$ & $0(0,0)$ & $8(100,0)$ & $0(0,0)$ & \\
\hline $13-14$ fev & 2 & $190,0 \pm 56,56,6$ & $56,6 \pm 27,4$ & $0(0,0)$ & $0(0,0)$ & $2(100,0)$ & $0(0,0)$ & \\
\hline Total & 27 & $186,6 \pm 40,8$ & $77,3 \pm 36,9$ & $0(0,0)$ & $1(3,7)$ & $25(92,6)$ & $1(3,7)$ & \\
\hline
\end{tabular}


período reprodutivo. A utilização da área para desova, no entanto, é ainda incerta.

\section{CONCLUSÕES}

Este relatório apresenta os dados preliminares de um estudo em andamento, sobre a ecologia populacional de $L$. plei nas regiões próximas à llha do Arvoredo sujeita à explotação por uma pescaria local. As principais conclusões foram:

1. A pesca artesanal de lula na llha do Arvoredo concentra-se na área do Saco do Capim que está situada fora dos limites da Reserva Biológica do Arvoredo.

2. A atividade tem importância significativa para as comunidade de Governador Celso Ramos porém é de natureza oportun ística, sendo regulada pela variação temporal das concentrações de lula e pela disponibilidade e preço de outros recursos pesqueiros durante o verão.

3. As concentrações de lulas exploradas devem constituir um grupo populacional homogêneo em atividade reprodutiva. Até o momento, não há evidências que permitam verificar se o do Saco do Capim é ou não utilizado como área de desova.

4. Regimes oceanográficos preferenciais podem estar relacionados a presença de lulas na região do Saco do Capim. Em particular deve-se ressaltar o fato das capturas nessa área terem ocorrido em associação com o deslocamento para SW das camadas superficiais e sub-superficiais da coluna de água e terem sido nulas em condições distintas.

Os resultados parciais apresentados nesse relatório sugerem um estudo mais aprofundado da estrutura populacional e das diversas possíveis causas naturais dessas concentrações . A proposta de trabalho para o verão 96-97 inclui o mesmo acompanhamento sistemático da pesca artesanal na área de entorno da llha do Arvoredo, além da investigação in situ das relações dessa atividade com os processos populacionais, relações tróficas e condições oceanográficas dominantes na região. Embora os principais focos de concentração da pesca de lula localizem-se fora das áreas de reserva biológica, é importante que se conheçam quais as relações dessa atividade com o ecossistema da reserva como subsídios para sua justificativa e possível regulamentação.

\section{AGRADECIMENTOS}

Os autores agradecem a colaboração das comunidades de Ganchos de Fora e localidades vizinhas em especial ao Leo, Laci e seus familiares. Este estudo foi executado com fundos da Faculdade de Ciências do Mar (UNIVALI). JAAP e JRB são bolsistas "recém-doutor" e de "iniciação científica", respectivamente, do CNPq.

\section{REFERÊNCIAS BIBLIOGRÁFICAS}

Bowden, K.F. 1983. Physical oceanography of coastal waters. New York, Ellis Horwood Limited.

Carvalho, J.L.B. \& C.A.F. Schettini. 1996. Contribuição ao estudo da estruturaoceanográfica do litoral centro-norte de Santa Catarina. Anais da 3a. Reunião Especial da SBPC- maio/96. UFSC, Florianóplis, SC. p. 406. (Resumos).

CEPSUL/ IBAMA 1994. Informe sobre os desembarques controlados de pescado no estado de Santa Catarina, nos anos de 1988 a 1992.100 p.

Coelho, M.L. 1985. Review of the influence of oceanographic factors on cephalopod distribution and life cycles. NAFO Sci. Counc. Studies 9:47-57.

Costa, P.A.S. \& M. Haimovici. 1990. A pesca de lulas e polvos no litoral do Rio de Janeiro. Ciência e Cultura. 42(12): 1124-1130. 
Guerra, A. \& G.P. Gandaras. 1983. Las pesquerias mundiales de cefalópodos: situación actual, perspectivas. Inf. Tec. Inst. Invest, Pesq., Barc., p. 102-104.

Haimovici, M. \& J.M. Andriguetto Fo. 1986. Cefalópodes costeiros capturados na pesca de arrasto do litoral sul do Brasil. Arq. Biol. e Tecnol. Parana, Curitiba, 29(3):473-495.

Haimovici, M. \& J.A.A. Perez. 1991. Abundância e distribuição de cefalópodes em cruzeiros de prospecção pesqueira demersal na plataforma externa e talude continental do Sul do Brasil. In: J.P. Castello \& M. Hainnovici [Eds.], Simpósio da FURG de Pesquisa Pesqueira. Attântica, 13(1): 189-200.

Juanicó, M. 1983. Squid nnaturity scales for population analysis. In: J.F. Caddy (ed.) Advances in assessment of world cephalopod resources. FAO Fish. Tech. Paper, 231: 341-378.
Haimovici, M. \& J.A.A. Perez. 1991b. The coastal cephalopod fauna of southern Brazil. Buli. Mar. Sci. 49 (1-2): 221-230.

Perez, J.A.A. 1996. A pesca de lula (Mollusca: Cephalopoda) em Santa Ca-tarina: histórico e perspectivas. Anais da $3 a$. Reunião Especial da SBPC $\neg$ maio/96. UFSC, Florianóplis, SC. p. 474. (Resumos).

Perez, J.A.A.; Schettini, C.A \& M.J Machado. 1996. A pesca de lulas (Mollusca: Cephalopoda) na llha do Arvoredo (SC): características e relações ecológicas. Anais da 3a. Reunião Especial da SBPCmaio/96. UFSC, Florianóplis, SC. p. 474. (Resumos). 
Anexo I. Formulário de entrevista empregado para coleta de dados da pesca artesanal de lulas no Município de Governador Celso Ramos durante o verão de 1996.

\section{Projeto LULAS - Pesca Artesanal}

Prof. Angel Perez - FACIMAR (UNIVALI) (047)

\section{4-7566}

\section{Dados de Pesca}

\section{Data:}

Local:

Embarcação:

Comprimento:

Localidade de origem:

Petrecho:

Sp-alvo:

Area de Pesca:

Regime de trabalho: noturno ( ) diurno (

Início da pescaria (h):

No. de horas sem pescar (abrigo):

Número de pescadores:

Pesca total $(\mathrm{kg})$ :

Local do desembarque:

Preço (R\$):

Observações
Tipo

Potência do Motor (HP):

Profundidade (m):

outros..

Fim da pescaria (h):

\section{Amostragem}

\section{Espécie:}

Número medido:

Número da amostra biológica:

Peso da Amostra

Observações

\section{Arte de Pesca - Zangarilho}

Tipo de linha:

Número de zangarilhos/ linha:

Material do zangarilho:

Tamanho do zangarilho:

Tipo de Luz:

Potência (w):

Esquema: 


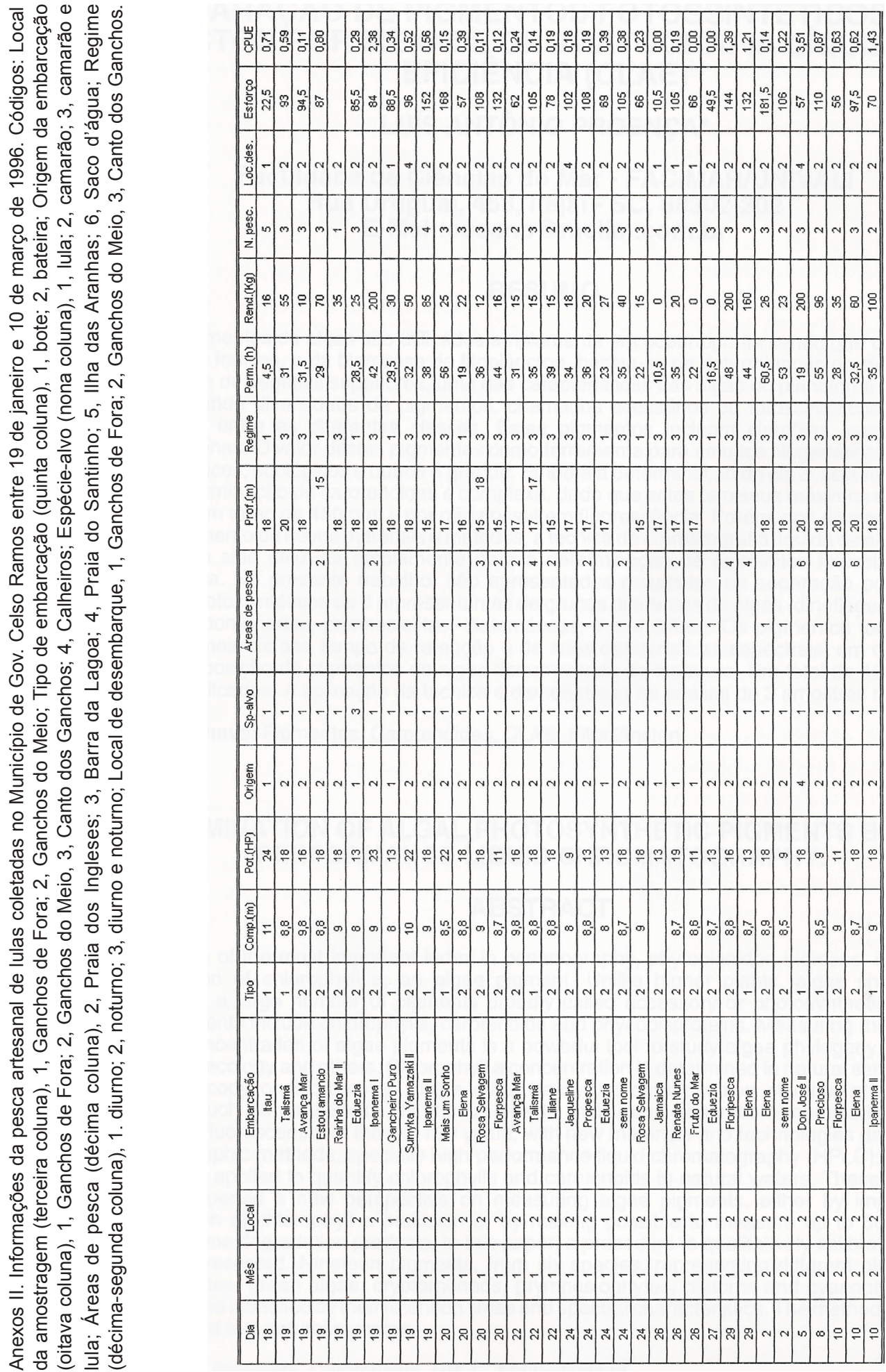


PEREZ et al.: A pesca de lulas na llha do Arvoredo. 